\title{
corrosión de tuberías
}

\author{
C. DEL OLMO, Lcdo. en Ciencias Químicas
}

\begin{abstract}
sinopsis
El presente trabajo aborda el tema de la corrosión de las tuberías empleadas en construcción. En él se enuncian unas consideraciones de carácter general sobre corrosión de tuberías, sin entrar ni en la cinética ni en los mecanis: mos propios de la corrosión, dándose a continuación unas recomendaciones de carácter práctico para evitar en lo posible este fenómeno tan generalizado y que tantas pérdidas ocasiona.

En la segunda parte del trabajo se incluye un cuestionario que consta de una serie de puntos cuyo conocimiento puede servir de base para el comienzo de una investigación sistemática sobre la causa o causas más probablemente determinantes de la corrosión de las tuberías. Complementan el cuestionario unas notas o comentarios a cada uno de los puntos tratados en el mismo.

Por último se facilitan en un apéndice final unos cuadros orientativos del contenido máximo permitido por la Instrucción para el proyecto y ejecución de obras de hormigón en masa o armado (Decreto 2.98\%/1968, de 20-IX-68) de los iones perjudiciales desde el punto de vista de la corrosión de las tuberías (sulfatos y cloruros) que habitualmente pueden encontrarse en el mortero u hormigón de cemento portland, haciendo resaltar la necesidad de rebajar estos contenidos si los materiales de construcción han de estar en contacto con tuberías de hierro.
\end{abstract}

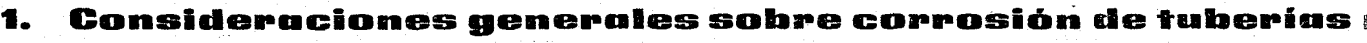

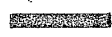

Las posibles causas de corrosión de una tubería pueden ser diversas.

Para poderlas determinar es necesario conocer, lo más exactamente posible, todas las condiciones ambientales que rodean a la tubería corroída, así como las particularidades de la instalación.

Es necesario tener en cuenta que el hierro, en general, y una tubería de hierro, en particular, se encuentra en un ambiente hostil que tratará de llevarle al estado de máxima estabilidad, es decir, a su estado primitivo de óxido, por lo que su durabilidad será tanto mayor cuanto mejor esté protegido contra la acción de este medio hostil, por medio de tratamientos superficiales, pinturas, aislamientos, etc., y cuanto más libre se encuentre de perturbaciones (tensiones mecánicas, térmicas, eléctricas, etc.).

Los agentes principalmente responsables de la corrosión del hierro son el oxígeno y el agua, actuando conjuntamente; ninguno de los dos (oxígeno seco o humedad exenta de oxígeno) es capaz, por separado, de producir corrosión.

Los materiales en contacto con una tubería de hierro de las comúnmente empleadas en construcción, recubiertas o empotradas en mortero, hormigón, terreno, etc., también pueden ser causa potencial de la corrosión, al contener agentes corrosivos; pero para que ésta tenga lugar es necesario la presencia del vehículo agua, el cual se suele manifestar en forma de condensaciones, humedades, etc. (1).

En general, una tubería sufre el efecto de la corrosión si es grande la humedad y pequeño el contenido de sales capaces de atacar la tubería (sulfatos, cloruros y nitratos preferentemente) existentes en el material en contacto con la tubería, en mayor grado que el caso contrario; es decir, cuando el contenido de dichas sales es elevado y el ambiente es seco.

(1) En ocasiones es suficiente el agua de amasado de los materiales de construcción, sin necesidad de agua del exterior, para que a través de ella emigren los iones agresivos (cloruros, p. e.) hasta el hierro y tenga lugar en este caso una corrosión por picaduras. 
Otras causas de corrosión son las heterogeneidades o desequilibrios que pueden afectar de alguna manera a las tuberías.

Estas heterogeneidades pueden ser de varios tipos; entre los que cabe citar los siguientes:

1.1. Heterogeneidades en la composición o constitución intrínseca (química, estructural o mecánica) de dos tramos de una tubería: Esta heterogeneidad aparece, por ejemplo, entre un tramo de tubería doblada en frío, en relación con el resto de la tubería que no ha sufrido deformación alguna (1). $O$ también puede aparecer entre la tubería y una zona de unión de la misma (manguito, codo, te, etc., de composición o tratamiento térmico distintos a los de la tubería) (2).

En estas condiciones, una zona de la tubería actúa como cátodo y la opuesta como ánodo, con la consiguiente destrucción, más o menos rápida, de la zona anódica, que coincide en general, en los dos casos anteriormente citados, con la tubería y no con los accesorios, y precisamente con el tramo de tubería doblado.

1.2. Heterogeneidades debidas a distinta aireación (corrosión conocida con el nombre de «corrosión por aireación diferencial»), se dan cuando dos zonas de una tubería reciben diferente aireación o ventilación (aporte de oxígeno). Esto ocurre:

1.2.1. Cuando una tubería empotrada atraviesa dos zonas de distinta porosidad (caso de recubrimiento de mortero de porosidad distinta, bien sea por su distinta composición, o por su distinta compacidad debida a diferencias en la puesta en obra).

1.2.2. Cuando atraviesa dos zonas de diferente estanquidad al paso del aire (por ejemplo, alicatado y pared).

1.2.3. Cuando se trata de una tubería con un diámetro de ciertas proporciones, donde una zona - la superior, si se trata de una tubería enterrada, o la más externa, en el caso de estar la tubería empotrada- está más aireada que la zona opuesta.

En estas condiciones la zona más aireada de la tubería actúa como cátodo produciéndose la destrucción de la zona menos aireada (ánodo), que en los ejemplos citados anteriormente sería: en el caso 1.2.1, el tramo de tubería en contacto con la zona de recubrimiento más compacto; en el 1.2.2, el protegido por el alicatado; y en el 1.2.3, la parte inferior de la tubería, en el primer supuesto, y la parte más interna, en el segundo (3).

1.3. Heterogeneidades debidas a diferencias de temperatura: En una instalación de calefacción se produce una diferencia de temperatura notable entre el tramo de tubería unido a la caldera y los tramos más distantes. Esta heterogeneidad puede ser causa de la corrosión del tramo de tubería sumergido en la zona caliente, que actúa de ánodo frente a la zona más fría de la tubería (cátodo).

La elevación de temperatura hace que se aceleren siempre los procesos de corrosión.

1.4. Heterogeneidades por diferencia de potencial entre dos zonas de una tubería: Se producen cuando a una zona de la misma llegan corrientes vagabundas, como consecuencia de aislamientos defectuosos que dan lugar a su fuga, lo cual constituye una causa importante de corrosión.

1.5. Heterogeneidades por diferencias en la composición del medio que rodea a la tubería: Este tipo de heterogeneidad se presenta, por ejemplo, cuando una tubería atraviesa una zona de mortero de cemento y otra de yeso; o en el caso de una tubería situada en un terreno, que contiene dos capas o zonas de desigual composición: arena y arcilla (4).

(1) Una tubería doblada en frío une, al efecto perjudicial de la creación de tensiones, la posible fisuración del galvanizado.

(2) Esta heterogeneidad apuntada puede afectar también a los tratamientos superficiales (galvanizado) de la tubería y los accesorios.

(3) No siempre este mecanismo de corrosión es el más activo, ni la zona de tubería corroída es precisamente la señalada. Así, en el caso 1.2.2 la zona de tubería corroída será la situada en contacto con la pared, si por efecto de condensaciones la tubería "se marca" a su paso por esta zona.

(4) En ocasiones, con motivo de una reparación hecha en un muro o tabique en el que está empotrada una tubería, se sustituye indebidamente el guarnecido primitivo (de mortero de cemento) de aquéllos por una capa de yeso, produciéndose un desequilibrio entre los dos electrólitos en que está embebida la tubería, con la consiguiente corrosión de la misma. 


\section{Recomend anciones}

A continuación se da una serie de recomendaciones que afectan a la durabilidad de las tuberías. Para una descripción más detallada consúltese el capítulo de «Fontanería y Saneamiento» de las Prescripciones del Instituto Eduardo Torroja (P.I.E.T.-70) y tratados de corrosión y protección de tuberías.

En general, el mortero u hormigón de cemento portland, libre de sales perjudiciales (sulfatos, cloruros y nitratos, principalmente), constituye una excelente protección de una tubería de hierro, si el material es muy compacto y homogéneo y de espesor suficiente para impedir el acceso de oxígeno y de humedad a la tubería.

En las condiciones anteriores de contacto de la tubería con los materiales de construcción, el tratamiento superficial de cinc, propio de las tuberías de acero galvanizado, es inoperante como protección del hierro a largo plazo, debido a que los materiales de construcción, húmedos, y dada su basicidad, corroen fuertemente al cinc; por lo tanto, de darse las condiciones que favorecen la corrosión, el tratamiento con cinc aplazaría únicamente el ataque del hierro, pero sin impedirlo.

En la fabricación del mortero u hormigón de protección de las tuberías de hierro deberá emplearse preferentemente cemento portland, se evitará el empleo de arena de playa y la utilización de aditivos que contengan cloruros, sulfatos y nitratos.

Los tubos se protegerán con papel, pintura, etc. En particular, se evitará todo contacto de los tubos de plomo con morteros de cemento, y el de los de acero galvanizado con morteros o pastas de yeso.

Se evitará, igualmente, el empleo de acero galvanizado en tuberías enterradas sin proteger.

En la red de distribución de agua caliente no deberán utilizarse tuberías de plomo, salvo en las acometidas de las tuberías a los grifos, y para las de plástico deberán tenerse en cuenta las limitaciones corres. pondientes a este tipo de material.

Cuando la presión de la red de agua fría pueda alcanzar los $8 \mathrm{kp} / \mathrm{cm}^{2}$, no deberán emplearse tuberías de plomo.

En edificios con juntas de dilatación, las tuberías no deberán pasar por éstas; pero, si ello fuera necesario, se emplearán juntas flexibles o dilatadores.

Para resolver las curvaturas, codos, injertos y derivaciones de una tubería se emplearán las piezas correspondientes que existen en el mercado.

No se permitirá centrar las tuberías utilizando piedras o calzos de madera.

Al atravesar un muro o forjado se emplearán pasamuros metálicos, de plástico o de cualquier otro material adecuado, de forma que dentro de ellos los tubos puedan deslizar.

Cuando las tuberías vayan empotradas en el muro se deberán hacer canales en él y no cerrarlos herméticamente, sino dejar rejillas de ventilación para evitar condensaciones -particularmente en regiones frías-.

Toda tubería de agua fría deberá quedar, por lo menos, a $4 \mathrm{~cm}$ de otra que conduzca agua caliente, y en recorridos horizontales irá por debajo de ellas para evitar condensaciones.

Se aislará toda tubería que pueda ser afectada por la proximidad de depósitos de agua caliente o cualquier otro foco de calor.

Los colectores deberán descansar sobre una solera de hormigón en los siguientes casos:

en terrenos con grava;

en terrenos poco firmes;

cuando haya tráfico en la superficie;

dentro del contorno de los edificios.

El tubo de acometida deberá quedar enterrado como mínimo a $75 \mathrm{~cm}$ del nivel superior del terreno. Si hubiese solera podrá disminuirse esta distancia a $50 \mathrm{~cm}$; pero, en ambos casos, deberá situarse por encima de cualquier tubo de saneamiento, siendo aconsejable mantener una distancia mínima de $30 \mathrm{~cm}$ entre ambas tuberías. 


\section{Euestionempio sobme composián de tuberíns}

Para poder precisar con mayor exactitud la causa o causas más probablemente determinantes de la corrosión de las tuberías, se incluye un cuestionario que consta de una serie de puntos cuyo conocimiento puede servir de base para el comienzo de una investigación sistemática de dichas causas.

1. Tiempo aproximado de funcionamiento de la instalación.

2. Material del que está fabricada la tubería: ¿es hierro, acero galvanizado, plomo, etc.?

3. Líquido que circula por la tubería: ¿es agua limpia u otro tipo de líquido? Indicar si se trata de una conducción sanitaria, un desagüe, etc.

4. El líquido que circula: ¿es frío o caliente? Indicar, si es posible, su temperatura.

5. Presión del líquido: ¿es normal o alta? Indicar, si es posible, la presión.

6. ¿Lleva la tubería algún tipo de soldadura?

7. ¿Presenta la tubería algún codo, curvatura u otro tipo de deformación hecha en frío?

8. La tubería está: ¿empotrada, enterrada, situada al aire o en cámara aislada?

9. Indicar si la tubería lleva algún tipo de protección (bituminoso, pintura, papel, etc.).

10. La tubería está en contacto con: ¿mortero u hormigón de cemento, yeso, terreno, etc.?

11. El mortero $u$ hormigón en contacto con la tubería: ¿está o podría estar fabricado con arena de playa? En caso afirmativo, ¿estaría ésta lavada?

12. El conglomerante del mortero u hormigón: ¿es cemento portland, o se trata de otro tipo de cemento (PAS, siderúrgico, de alto horno, puzolánico, aluminoso, etc.)?

13. El mortero u hormigón: ¿lleva incorporado algún aditivo? En caso afirmativo, indicar, si es posible, su naturaleza, nombre comercial y proporción en que forma parte del material.

14. El mortero de hormigón, a simple vista: ¿es compacto o poroso?

15. El terreno en el que está enterrada la tubería: ¿es arcilloso, arenoso, con grava, poco firme, etc.?

16. A dicho terreno: ¿llegan o pueden llegar aguas residuales?

17. Indicar el espesor (aproximado) del empotramiento o enterramiento de la tubería.

18. Ambiente exterior a la tubería: ¿es muy húmedo, seco, húmedo y salino (próximo al mar, depósito salino o lugar donde, por ejemplo, se conserven alimentos con sal)? Otro tipo de ambiente: ¿es industrial con humos, gases o vapores $\left(\mathrm{SO}_{2}\right)$, etc.?

19. La tubería: ¿se encuentra afectada por condensaciones, humedades, fugas de agua o de otros líquidos, goteras, etc.?

20. Indicar si la tubería de agua fría está próxima a otra de agua caliente. En caso de conducción horizontal, si está situada encima o debajo de la caliente.

21. ¿Atraviesa la tubería alguna junta de dilatación del edificio?

22. ¿Soporta la tubería algún peso, es decir, está bajo tensión?

23. La zona de la tubería afectada por la corrosión: ¿podría sufrir el efecto de corrientes vagabundas (estar, por ejemplo, cercana al paso de tranvías o trenes eléctricos), o estar próxima a cables eléctricos desprovistos de aislamiento?

24. En las tuberías de calefacción indicar la distancia (aproximada) de la caldera a la zona corroída.

25. En las tuberías de calefacción indicar, si es posible, el tiempo transcurrido desde que fueron recubiertas de hormigón (si es ese el caso) y su puesta en servicio a temperaturas elevadas.

26. En edificios recién inaugurados, en los que se ha observado corrosión de tuberías empotradas en el suelo: ¿podría haberse empleado en la limpieza de sus suelos alguna lejía o ácido?

27. En mercados, industrias, etc., las tuberías empotradas en el suelo, ¿están suficientemente protegidas?

28. ¿Qué zona de la tubería, en relación con su posición en la instalación, se encuentra más afectada por la corrosión?: ¿la parte superior o la inferior de la tubería? 


\section{Notas al cuestionerio sobme composión cle tubericas}

1. El período de vida media de una instalación de saneamiento realizada en condiciones óptimas, se estima en unos 50 años.

2. No deben utilizarse tuberías de plomo en contacto con mortero de cemento, ni cuando la presión en la red de agua fría pueda alcanzar los $8 \mathrm{kp} / \mathrm{cm}^{2}$.

No debe emplearse acero galvanizado en contacto con yeso ni en tuberías enterradas sin proteger.

3. El líquido que circula por una tubería puede influir en la corrosión interior de la misma, no en la exterior, si ésta es completamente estanca y no presenta fugas.

4. Una temperatura elevada incrementa los procesos de corrosión y los ciclos alternativos de calor-frío aún más. A temperatura superior a $70^{\circ} \mathrm{C}$ se ataca el galvanizado, actuando éste en sentido contrario al de la protección, es decir, acelerando los procesos de corrosión.

5. Una presión elevada puede originar movimientos en la tubería, y si no está bien sujeta podrían aflojar las juntas de la misma, con la consiguiente pérdida de líquido y la correspondiente corrosión. Por ello es necesario probar a presión (tanto en frío como en caliente) las tuberías para comprobar su estanquidad antes de recubrirlas.

6. En general, deben evitarse las soldaduras en tuberías galvanizadas, por el peligro que existe de que se perjudique el galvanizado (a la vez que se forman heterogeneidades en la tubería); por lo tanto, sólo se permitirá emplear la soldadura fuerte cuando se garantice que el galvanizado no quedará dañado.

7. La tubería no debe doblarse en frío, por el peligro que existe de fisurar el galvanizado, además de crear tensiones en la tubería que pueden dar lugar a corrosión.

Para resolver las curvaturas, codos, injertos y derivaciones de una tubería deben emplearse las piezas correspondientes que existen en el mercado.

8. Se recomienda que las tuberías empotradas vayan en canales o cámaras ventiladas si la humedad ambiente es muy elevada, a fin de evitar condensaciones sobre ellas. En caso contrario pueden ir embebidas en mortero u hormigón.

9. Cualquier tipo de protección es muy conveniente para evitar en lo posible la corrosión.

10. En general, se evitará el contacto directo de la tubería con los materiales de construcción, teniendo especialmente en cuenta lo indicado en el apartado segundo.

11. El mortero deberá ser de cemento portland, se evitará el empleo de arena de playa y de áridos con

11. impurezas capaces de oxidar localmente las tuberías (por ejemplo, escorias porosas que contengan

12. cantidades no despreciables de sulfuros de hierro o calcio y sulfatos) y así como la utilización de

13. aditivos que contengan cloruros, nitratos y, en general, electrólitos.

14. El mortero deberá ser muy compacto y homogéneo y de espesor suficiente para impedir el acceso de oxígeno y de humedad a la tubería.

15. Es imprescindible proteger los tubos galvanizados enterrados. En terrenos de grava y poco firmes, las tuberías deberán descansar sobre solera de hormigón.

16. Siempre que una conducción haya de atravesar un terreno, es necesario hacer un estudio previo del mismo, determinando principalmente: el $\mathrm{pH}$, la resistividad, el contenido de humedad y de sales perjudiciales (sulfatos, cloruros, nitratos y sulfuros); y a la vista de los resultados obtenidos obrar en consecuencia.

En el caso de que a dicho terreno lleguen aguas residuales, es imprescindible tomar precauciones especiales. Se procurará desviar el vertedero de la conducción, o ésta de aquél (según la dificultad que esta operación encierre), lo máximo posible.

(*) La numeración de cada comentario se corresponde con el número de la pregunta hecha en el Cuestionario precedente. 
En casos como el citado, se han aplicado con éxito las siguientes medidas de protección de las tuberías enterradas, solas o en conjunción unas con otras:

Enmienda del terreno, que consiste en rodear el circuito con arena hasta unos $20 \mathrm{~cm}$ de espesor, mezclando, en casos muy críticos, de 3 a $10 \mathrm{~kg}$ de cal viva por $\mathrm{m}^{3}$ de tierra terraplenada.

Colocar la tubería en una fosa o trinchera llena de ladrillos porosos, grava o arena.

Situar la tubería en una larga «caja» que se llena de hormigón bien compactado.

Pintar la tubería con betún o alquitrán.

17. En general, la protección de una tubería, por lo que se refiere al mortero u hormigón, reside más en la calidad, compacidad e impermeabilidad de estos materiales que en el espesor de la capa protectora.

Puede servir de pauta para establecer la dimensión mínima que debe tener la capa protectora de mortero u hormigón, lo indicado para las armaduras de hormigón. Un cuadro (IV) con estas dimensiones mínimas se inserta al final del presente trabajo.

El tubo de acometida deberá quedar enterrado a $75 \mathrm{~cm}$ del nivel superior del suelo; si hubiese solera, podrá disminuirse esta distancia a $50 \mathrm{~cm}$.

18. En ambientes muy húmedos, y sobre todo húmedos y salinos, es imprescindible tomar precauciones especiales.

Da mejor resultado en ambientes muy húmedos situar las tuberías en canales bien ventilados que empotrarlas en materiales de construcción, ya que éstos son permeables al agua en mayor o menor medida. Cuando además el ambiente es salino, es necesario también que las tuberías vayan protegidas con pintura plástica.

Se recomienda, como medida complementaria, colocar recipientes con cal viva $\mathrm{u}$ otras materias absorbentes del agua para eliminar o disminuir la condensacia de la humedad.

En ambientes industriales con humos, gases o vapores (por ejemplo $\mathrm{SO}_{2}$ ), etc., se recomienda ampliar al máximo las precauciones aumentando el espesor de los empotramientos en que van situadas las tuberías, proteger éstas con las pinturas plásticas citadas anteriormente o con recubrimiento de silicona, plástico o de caucho. Se estudiará en este caso si conviene que las tuberías estén ventiladas o no.

19. Hay que evitar siempre las condensaciones, fugas, goteras, etc., que afecten o puedan afectar a las tuberías.

20. Toda tubería de agua fría deberá quedar, por lo menos, a $4 \mathrm{~cm}$ de otra que conduzca agua caliente, y en recorridos horizontales irá por debajo de ella para evitar condensaciones.

21. Las tuberías no deberán pasar a través de las juntas de dilatación de los edificios; y si esto fuera imprescindible se emplearán juntas flexibles o dilatadores.

22. Las tuberías se instalarán de tal forma que no soporten carga ni tensión alguna.

23. Es imprescindible aislar debidamente toda conducción eléctrica, en especial los cables próximos a zonas metálicas. Puede existir el peligro de corrosión por corrientes vagabundas si una tubería de hierro es utilizada para "toma de tierra» (masa) de una instalación eléctrica.

Cuando un terreno, en el que van a estar o están enterradas tuberías, está sometido al trastorno que suponen las corrientes vagabundas, es necesario eliminar éstas lo mejor posible para evitar esta fuente segura de corrosión.

Varias soluciones se han puesto en práctica, en casos como el expuesto, para evitar este peligro, entre las que cabe destacar: drenajes eléctricos, uniones aislantes, empleo de barras anódicas de sacrificio y protección catódica. Una descripción detallada de los métodos de lucha contra este tipo de corrosión pueden encontrarse en la bibliografía que se inserta en el capítulo correspondiente del presente trabajo.

24. Es necesario aislar las zonas de la tubería próximas a las calderas.

25. Algunos autores aconsejan dejar tiempo suficiente para que el hormigón fragüe y endurezca debidamente antes de poner en funcionamiento la instalación de agua caliente. Esta recomendación se funda en el hecho de que la película de óxido de hierro, de composición variable, protectora de la corrosión, que se forma al poner la tubería en contacto con el hormigón, será tanto menos porosa y, por lo tanto, protegerá la tubería en mayor medida cuanto mayor sea el tiempo que ha tardado en formarse, y menor la temperatura a que ha tenido lugar su formación.

26. En la limpieza de suelos no es aconsejable emplear lejías ni ácidos para eliminar los restos de cemento, escayola, pintura, etc., que quedan o pueden quedar sobre ellos después de una obra, sobre todo cuando están situadas las tuberías debajo del pavimento, por el peligro que existe de que lleguen 
a ellas estos líquidos corrosivos. Como se sabe, si la limpieza se realiza antes de que estos materiales se adhieran fuertemente al suelo, es suficientemente el agua para eliminarlos.

27. En mercados, industrias, etc., donde es habitual que fluyan aguas residuales agresivas, es imprescindible proteger las tuberías situadas en el suelo de dichos locales si se quiere evitar la corrosión de las mismas.

Se colocarán las tuberías, pintadas con pintura, betún o alquitrán, en una caja o fosa de hormigón bien compacto sobre la que irá colocado, a ser posible, un pavimento de baldosas.

28. La situación de la zona de tubería corroída, dentro de la instalación general, puede dar alguna indicación de las causas que han motivado dicha corrosión. Para ello puede tenerse en cuenta lo indicado en los apartados 1.2.1, 1.2.2 y 1.2.3 del presente trabajo.

\section{Conelusiones}

Del conocimiento de los factores que pueden ser causas determinantes o coadyuvantes de la corrosión de las tuberías se desprende la necesidad de evitarlos lo mejor posible, mediante la aplicación de un código de buena práctica que comprenda: a la tubería como material, a la instalación y a su recubrimiento, el cual deberá ser un material adecuado hecho en condiciones óptimas.

Se deberá disminuir el contenido de los iones perjudiciales (en especial cloruros y sulfatos) permitido por la vigente Instrucción para el Proyecto y Ejecución de Obras de Hormigón en masa o armado, cuando estos materiales hayan de estar en contacto con tuberías de hierro, sobre todo en ambientes muy húmedos $\mathrm{y}$, en especial, en morteros $\mathrm{u}$ hormigones muy ricos en cemento y de consistencia fluida (con gran proporción de agua).

No obstante todo lo expuesto a lo largo del presente trabajo, planteada la corrosión desde el punto de vista económico, se verá si resulta rentable en cada caso tomar excesivas precauciones para aislar al má. ximo las tuberías o si, por el contrario, conviene más proceder a sustituirlas cuando sea necesario.

\section{4 pínendiee}

Datos orientativos del contenido máximo (según las normas vigentes) de los iones (capaces de producir la corrosión de las tuberías) presentes en un mortero u hormigón fraguado (*).

CUADRO I. \% de sulfatos, expresados en $\mathrm{SO}_{3}$, contenidos en un mortero u hormigón fraguado.

\begin{tabular}{|c|c|c|c|c|c|c|}
\hline \multirow{3}{*}{$\begin{array}{c}\text { Dosificaciones } \\
\text { del mortero } \\
\text { u hormigón } \\
\left(\mathrm{kg} / \mathrm{m}^{3}\right)\end{array}$} & \multirow{3}{*}{$\begin{array}{l}\text { Para las densidades } \\
\text { del mortero } \\
\text { u hormigón } \\
\text { siguientes } \\
\left(\mathrm{kg} / \mathrm{dm}^{3}\right)\end{array}$} & \multicolumn{3}{|c|}{$\begin{array}{c}\% \mathrm{SO}_{3} \text { aportado por los constituyentes del mortero } \\
\text { u hormigón }\end{array}$} & \multirow{2}{*}{\multicolumn{2}{|c|}{$\begin{array}{c}\% \mathrm{SO}_{3} \text { total en el mortero } \\
\text { u hormigón } \\
\text { para Relación a/c: }\end{array}$}} \\
\hline & & \multirow{2}{*}{ Cemento (1) } & \multicolumn{2}{|c|}{$\begin{array}{c}\text { Agua (2) } \\
\text { Relación a/c: }\end{array}$} & & \\
\hline & & & 0,6 & 0,9 & 0,6 & 0,9 \\
\hline \multirow{2}{*}{450} & $d=2,1$ & 0,86 & 0,011 & 0,016 & 0,87 & 0,88 \\
\hline & $d=2,3$ & 0,78 & 0,010 & 0,015 & 0,79 & 0,80 \\
\hline \multirow{2}{*}{350} & $d=2,1$ & 0,67 & 0,008 & 0,0125 & 0,68 & 0,68 \\
\hline & $d=2,3$ & 0,61 & 0,008 & 0,012 & 0,62 & 0,62 \\
\hline \multirow{2}{*}{250} & $\mathrm{~d}=2,1$ & 0,476 & 0,006 & 0,009 & 0,48 & 0,49 \\
\hline & $d=2,3$ & 0,434 & 0,005 & 0,008 & 0,44 & 0,44 \\
\hline
\end{tabular}

(1) $\% \mathrm{SO}_{3}$ del cemento: 4,0 .

(2) $\% \mathrm{SO}_{3}$ del agua: $0,83 \mathrm{~g} /$ litro.

(*) Por fenómenos de difusión o electroquímicos puede producirse una emigración de estos iones agresivos hacia la zona del mortero $u$ hormigón en contacto con la tubería, por lo que en las proximidades de la misma es posible encontrar un enriquecimiento de estos iones, a expensas de los del resto de la masa de mortero u hormigón. 
CUADRO II. \% de cloruros expresados en $\mathrm{Cl}^{-}$, contenidos en los componentes de un mortero u hormigón fraguado $\mathrm{y}$ en dos proporciones del aditivo $\mathrm{Cl}_{2} \mathrm{Ca}$.

\begin{tabular}{|c|c|c|c|c|c|c|c|c|c|c|}
\hline \multirow{4}{*}{$\begin{array}{l}\text { Dosifica- } \\
\text { ciones del } \\
\text { mortero u } \\
\text { hormigón } \\
\left(\mathrm{kg} / \mathrm{m}^{3}\right)\end{array}$} & \multirow{4}{*}{$\begin{array}{c}\text { Para las den- } \\
\text { sidades del } \\
\text { mortero } \\
\text { u hormigón } \\
\text { siguientes } \\
\left(\mathrm{kg} / \mathrm{dm}^{3}\right)\end{array}$} & \multicolumn{7}{|c|}{$\% \mathrm{Cl}^{-}$aportado por los componentes del mortero u hormigón } & \multicolumn{2}{|c|}{$\begin{array}{l}\% \mathrm{Cl}^{-} \text {aportado por } \\
\text { el aditivo } \mathrm{Cl}_{2} \mathbf{C a}\end{array}$} \\
\hline & & \multirow{3}{*}{$\begin{array}{l}\text { Cemento } \\
\text { (1) }\end{array}$} & \multicolumn{3}{|c|}{ Agua } & \multicolumn{3}{|c|}{ Relación a/c } & \multirow{3}{*}{$1,5 \%$} & \multirow{3}{*}{$2,0 \%$} \\
\hline & & & \multicolumn{3}{|c|}{0,6} & \multicolumn{3}{|c|}{0,9} & & \\
\hline & & & (2) & (3) & (4) & (2) & (3) & (4) & & \\
\hline \multirow{2}{*}{450} & $\mathrm{~d}=2,1$ & 0,064 & 0,013 & 0,077 & 0,309 & 0,019 & 0,116 & 0,463 & 0,205 & 0,273 \\
\hline & $d=2,3$ & 0,059 & 0,012 & 0,070 & 0,282 & 0,017 & 0,105 & 0,423 & 0,187 & 0,250 \\
\hline \multirow{2}{*}{350} & $\mathrm{~d}=2,1$ & 0,050 & 0,010 & 0,060 & 0,240 & 0,015 & 0,090 & 0,360 & 0,159 & 0,213 \\
\hline & $d=2,3$ & 0,046 & 0,009 & 0,055 & 0,219 & 0,014 & 0,082 & 0,329 & 0,146 & 0,194 \\
\hline \multirow{2}{*}{250} & $\mathrm{~d}=2,1$ & 0,036 & 0,007 & 0,043 & 0,170 & 0,011 & 0,064 & 0,256 & 0,114 & 0,152 \\
\hline & $d=2,3$ & 0,032 & 0,006 & 0,039 & 0,156 & 0,010 & 0,059 & 0,235 & 0,104 & 0,139 \\
\hline
\end{tabular}

(1) $\% \mathrm{Cl}^{-}$del cemento: 0,3 (contenido aproximado).

(2) \% $\mathrm{Cl}^{-}$del agua: $1 \mathrm{~g} / \mathrm{litro}$.

(3) $\% \mathrm{Cl}^{-}$del agua: $6 \mathrm{~g} /$ litro.

(4) $\% \mathrm{Cl}^{-}$del agua: $24 \mathrm{~g} /$ litro (para hormigones en masa).

NOTA: Los \% de $\mathrm{Cl}^{-}$de las aguas de los apartados (3) y (4) corresponden a los máximos contenidos de este ion admitidos en las aguas de amasado y curado de hormigones, según la Instrucción vigente.

CUADRO III. \% de cloruros totales, expresados en $\mathrm{Cl}^{-}$, contenidos en un mortero u hormigón fraguado.

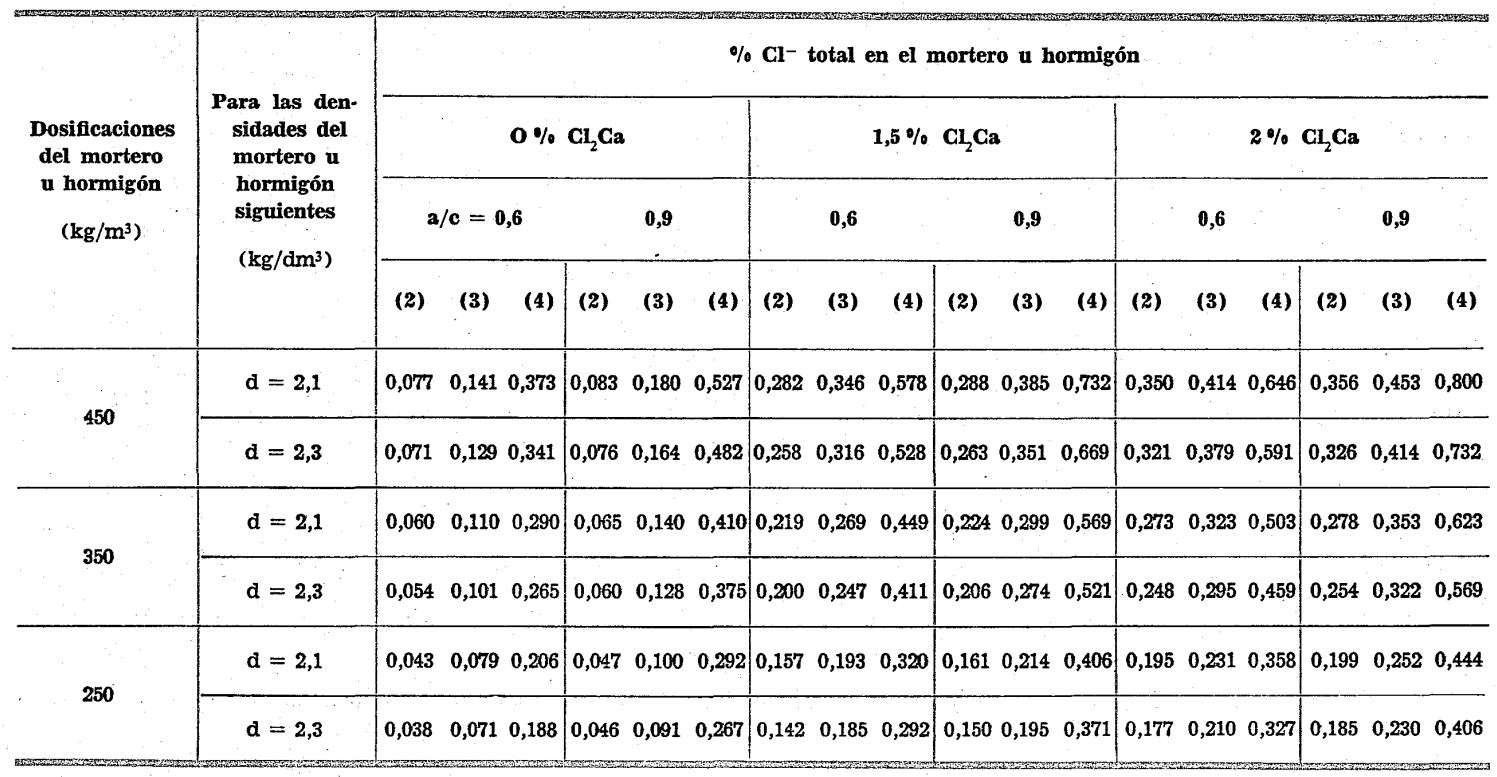

(2) $\% \mathrm{Cl}^{-}$del agua: $1 \mathrm{~g} /$ litro.

(3) $\% \mathrm{Cl}^{-}$del agua: $6 \mathrm{~g}$ /litro.

(4) \% $\mathrm{Cl}^{-}$del agua: $24 \mathrm{~g} / \mathrm{litro}$ (para hormigones en masa).

$\% \mathrm{Cl}^{-}$del cemento: 0,3 (contenido aproximado). 
Fig. 2. Tubería de acero galvanizado en contacto con mortero de cemento portlavar. sión por picaduras, propia de cloruro-

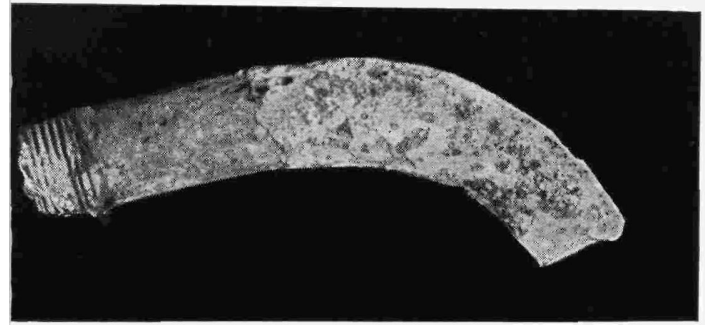

Fig. 1. Tubería de acero galvanizado en contacto con yeso. En ella ha tenido lugar una corrosión por sulfatos. En el caso de la figura, al efecto anterior se suma el de las tensiones in

3

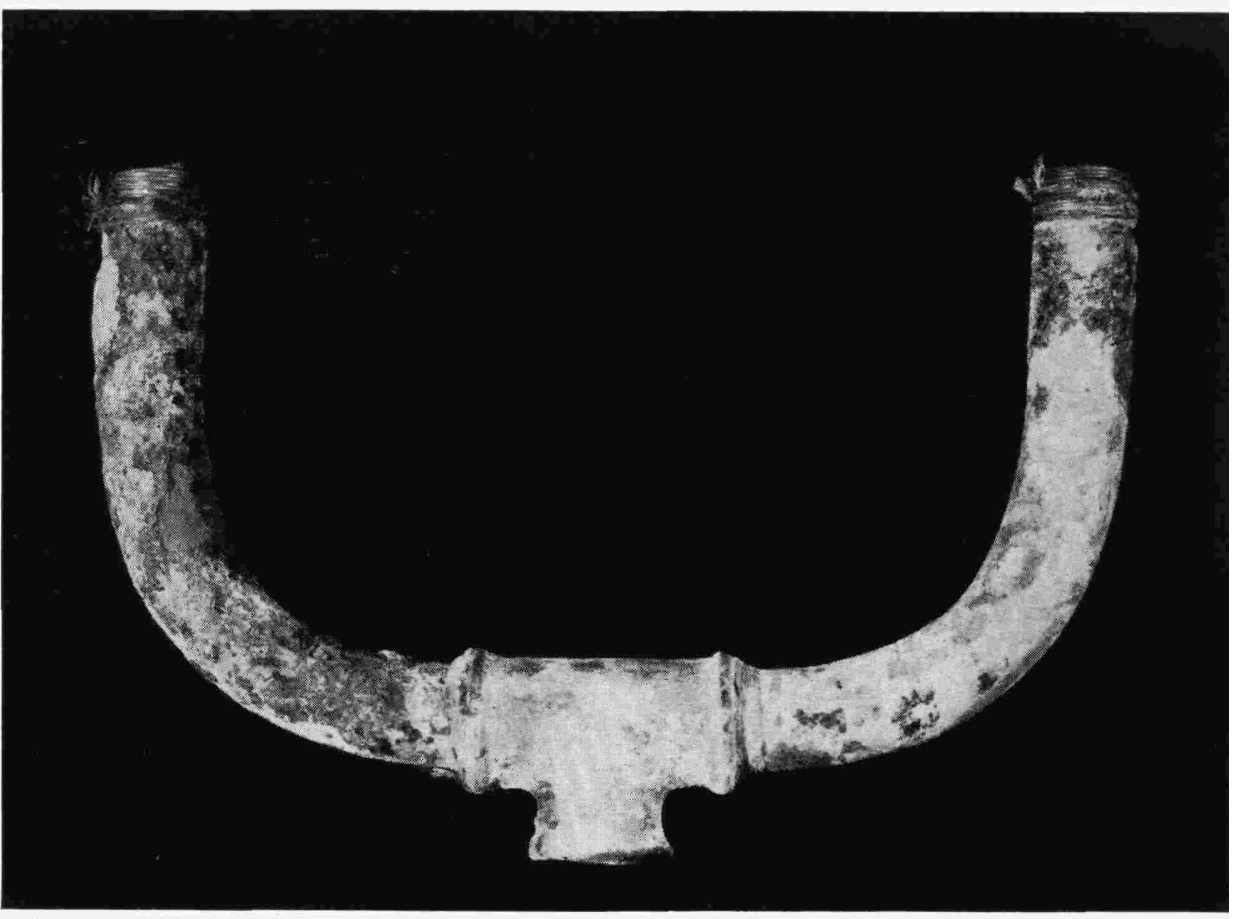

Figs. 3 y 3'. Tuberías de acero galvanizado embebidas en mortero de ce mento portland, compacto y sin iones agresivos. La corrosion observada ha sic reso de la tuberí de la firura 3 a este la tuberia de la figura 3 , a este efecto. se superpor da

la zona de tubería doblada.

Fig. 4. Nuevo ejemplo de tubería de acero galvanizado, en la que el tram de tubería doblado (ánodo: zona de disolución del metal) ha sufrido el efecto de la corrosion en contrapunto con el resto de la tubería libre de tensiones (cátodo).

\section{Corrosidi die thulberías}

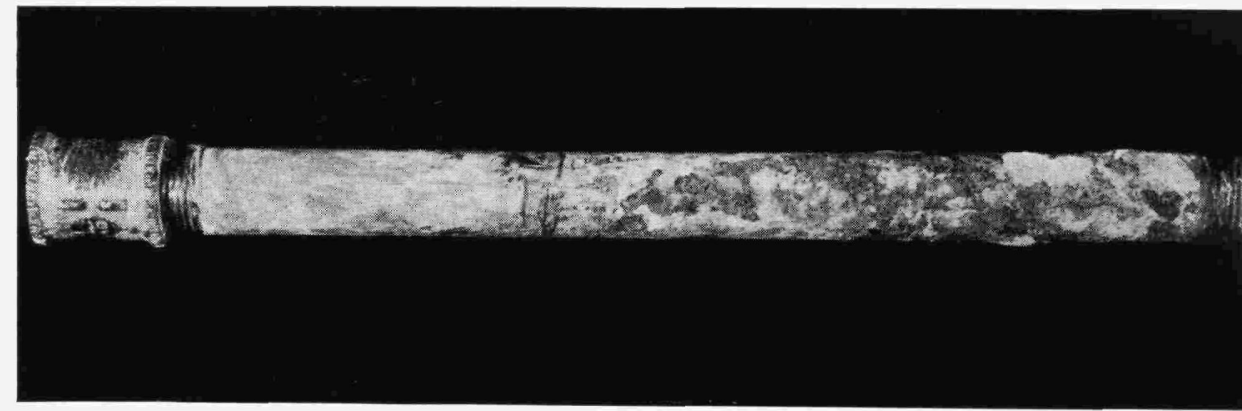

4

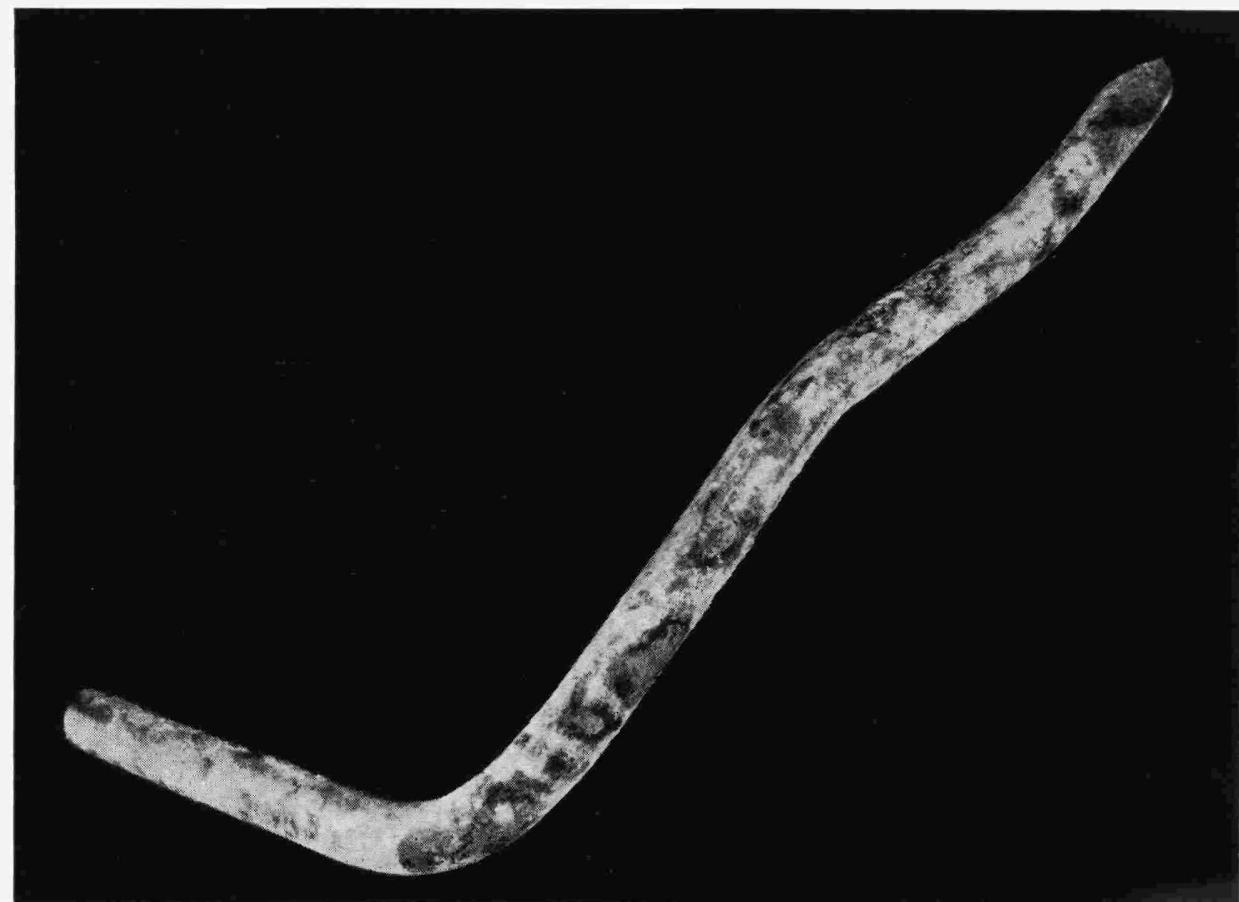


CUADRO IV. Valores orientativos del espesor mínimo que debe tener el recubrimiento de mortero u hormigón de una tubería de hierro para que su protección sea eficaz (1).

\begin{tabular}{|c|c|c|c|}
\hline $\begin{array}{c}\text { Distancias mínimas a las paredes del encofrado o a la superficie } \\
\text { lisa del hormigón }\end{array}$ & $\begin{array}{l}\text { Valor mínimo } \\
\text { absoluto }\end{array}$ & $\begin{array}{l}\text { Valor referido al } \\
\text { diámetro del con- } \\
\text { torno aparente de } \\
\text { la barra más } \\
\text { gruesa }(2)\end{array}$ & $\begin{array}{l}\text { Valor referido } \\
\text { a la dimensión } \\
\text { máxima del árido }\end{array}$ \\
\hline $\begin{array}{l}\text { Elementos de obras interiores, en un ambiente estable y } \\
\text { no corrosivo. }\end{array}$ & $1 \mathrm{~cm}$ & $1 \mathrm{vez}$ & $1 \mathrm{vez}$ \\
\hline $\begin{array}{l}\text { Elementos de obras exteriores protegidos contra la lluvia } \\
\text { o la helada en el estado de saturación. } \\
\text { Obras enterradas en un suelo no corrosivo. }\end{array}$ & $2 \mathrm{~cm}$ & 2 veces & $1 \mathrm{vez}$ \\
\hline $\begin{array}{l}\text { Elementos de obras interiores expuestos a humos o a } \\
\text { gases corrosivos. }\end{array}$ & & & \\
\hline $\begin{array}{l}\text { Elementos de obras exteriores expuestos a influencias at- } \\
\text { mosféricas intensas (tales como fuertes precipitaciones, } \\
\text { alternancias de humedad y de sequedad pronunciadas en } \\
\text { estado de saturación). }\end{array}$ & $3 \mathrm{~cm}$ & 1,25 veces & 1,5 veces \\
\hline $\begin{array}{l}\text { Elementos expuestos a heladas intensas y a la acción de } \\
\text { sal para el deshielo. }\end{array}$ & & & \\
\hline $\begin{array}{l}\text { Elementos de obras que deben presentar una resistencia } \\
\text { particular bien a los agentes químicos, bien a la abrasión. }\end{array}$ & \multicolumn{3}{|c|}{$\begin{array}{l}\text { La distancia mínima debe ser fijada por el } \\
\text { Ingeniero-Provectista. }\end{array}$} \\
\hline
\end{tabular}

(1) Estos valores han sido tomados de la Propuesta de Recomendaciones Internacionales para el Cálculo y Ejecución de Obras de Hormigón - mayo 1970—, por similitud con el problema tratado, y se refieren al espesor de la capa de protección de las armaduras.

(2) Tubería de hierro en el presente caso.

\section{Bibliog rafía}

BiczoK, I.: "Concrete Corrosion and Concrete Protection". Budapest, 1964.

CAlleja, J.: "La corrosión de las armaduras en los hormigones armados y pretensados". Rilem Symposium Durability of Concrete 1969, Praga, y Monografía núm. 256 (I.E.T.c.c.). Madrid, 1966.

Calleja, J., y Andrade, C.: "Estudio de la corrosión del acero en el hormigón". Universidad de Madrid, julio 1970. Evans, Ulick R.: "Introducción a la corrosión metálica”. Ed. Marín, 1950.

Johansson, A.: "Corrosion of Pipes Embeded in Concrete". Rilem Symposium Durability of Concrete, 1969. Praga. Madrin, Alexandre J.: "Manual de Anticorrosión". Ed. Urmo, 1966.

Scully, J. C.: "Fundamentos de la corrosión". Ed. Alhambra, S. A., 1968.

ТоDт, Fritz: “Corrosión y Protección”. Ed. Aguilar, 1959.

UHLIG: "Corrosion Handbook". 1948.

Venuat, M., y Papadakis, M.: "Control y ensayo de cementos, morteros y hormigones”. Ed. Urmo, 1966.

Prescripciones del Instituto "Eduardo Torroja" (P.I.E.T. - 70). Fontanería y Saneamiento.

"Corrosión de tuberías enterradas". Publicación de la Sociedad Civil de Empresas Suministradoras de Aguas, 1964. "Symposium on corrosion fundamentals". The University of Tennessee Press, 1956.

"Propuesta de recomendaciones internacionales para el cálculo y ejecución de obras de hormigón CEB-FIP". Mayo 1970.

"Instrucciones para el proyecto y ejecución de obras de hormigón en masa" (Decreto 2.987/1968, de 20 de septiembre de 1968).

"Pliego de Condiciones para la recepción de conglomerantes hidráulicos" (P.C.C.H. - 64). Manuales y Normas del I.E.T.C.c., 1964. 


\section{Gorrosion des tugunteries}

C. del Olmo, licencié ès Sciences Chimiques

L'auteur aborde, dạs cet article, le problème de la corrosion des tuyauteries utilisées dans le bâtiment et en énonce des considérations de caractère général, sans faire allusion à la cinétique ni aux mécanismes propres à la corrosion. Il donne ensuite des recommandations pratiques pour éviter, dans la mesure du possible, ce phénomène si généralisé et qui occasionne tant de pertes.

La deuxième partie de ce travail inclut un questionnaire qui comporte une série de points dont la connaissance peut servir de base au commencement d'une recherche systématique sur la ou les causes probablement les plus déterminantes de la corrosion des tuyauteries. Ce questionnaire est complété par des commentaires sur chacun des points évoqués.

Finalement, l'auteur présente dans un appendice quelques tableaux explicatifs de la teneur maximale, permise par l'Instruction pour le projet et exécution d'ouvrages en béton en masse ou armé (Décret 2.987/1968 du 20-1X-68), des ions nuisibles du point de vue de la corrosion des tuyauteries (sulfates et chlorures), existant généralement dans le mortier ou le béton de ciment portland, et souligne la nécessité de réduire ces teneurs pour les cas où les matériaux de construction doivent entrer en contact avec les tuyauteries en fer.

\section{Pipe comosiom}

C. del Olmo, graduate in Chemistry

This paper deals with the corrosion of pipes used in construction. General aspects of pipe corrosion are dealt with, without discussing either the kinetics or detailed phenomena of corrosion. General advise is given on practical measures to avoid as far as possible the development of corrosion, a problem which is both widespread and extremely expensive.

The second part of the publication includes a questionnaire containing a number of points, whose ellaboration may serve as starting point for a systematic study on the most likely causes of pipe corrosion. A number of notes or comments are also added to each of the above points.

Finally there is an appendix with tables, giving construction specifications data on permissible maxima for harmful ions applicable to mass or reinforced concrete for pipe construction (Law $298 \% / 1968$, of 20-IX-68). This refers to sulphate and chlorate ions which normally may be present in portland cement and concrete. It is emphasized that these contents should be kept low if the cement or concrete is going to be in contact with iron pipes.

\section{Komposion in Rohrleitungem}

c. del Olmo, Diplom-Chemiker

Vorliegender Beitrag befasst sich mit dem Thema der Korrosion in den im Baugewerke zum Einsatz kommenden Rohrleitungen. Es werden einige allgemeine Betrachtungen angestellt über die Korrosion in Rohrleitungen, ohne dass jedoch auf die Kinetik noch auf die der Korrosion eigenen Mechanismen eingegangen wird. Anschliessend werden einige Empfehlungen praktischer Art gegeben, um dieses so häufige Phänomen, dass so viele Verluste mit sich bringt, zu vermeiden.

Im zweiten Teil dieses Beitrags ist ein Fragebogen enthalten, der aus einer Reihe von Punkten besteht, deren Kenntnis als Grundlage dienen kann für den Beginn einer systematischen Untersuchung der Ursache oder Ursachen, die aller Wahrschein. lichkeit nach am entscheidensten sind für die Korrosion in Rohrleitungen. Der Fragebogen wird etgänzt durch eine Reihe von Kommentaren und Randbemerkungen zu den verschiedenen, darin behandelten Punkten.

Im Anhang werden abschliessend einige Tabellen angeführt, die über den maximal den geltenden Vorschriften gemäss zulässigen Gehalt an Ionen, bei der Planung und Durchführung von Bauten aus massivem oder Stahlbeton (Erlass 2.987/1968, vom 20.9.68), die sich, vom Standpunkt der Korrosion in Rohrleitungen aus gesehen (Sulfate und Chloride), als schädlich erweisen und gewöhnlich im Mörtel und Beton aus Portland-Zement auftreten können; hierbei wird auf die Notwendigkeit hingewiesen, diesen Gehalt herabzumindern, falls die Baumaterialien in direkten Kontakt mit Eisenrohren kommen. 